\title{
Changes in global air pollutant emissions during the COVID-19 pandemic: a dataset for atmospheric chemistry modeling
}

5 Thierno Doumbia ${ }^{1}$, Claire Granier ${ }^{1,2}$, Nellie Elguindi ${ }^{1}$, Idir Bouarar $^{3}$, Sabine Darras ${ }^{4}$, Guy Brasseur $^{3,5}$, Benjamin Gaubert ${ }^{5}$ Yiming Liu $^{6}$, Xiaoqin Shi ${ }^{3}$, Trissevgeni Stavrakou ${ }^{7}$, Simone Tilmes $^{5}$, Forrest Lacey ${ }^{5}$, Adrien Deroubaix ${ }^{3}$, Tao Wang ${ }^{6}$

${ }^{1}$ Laboratoire d'Aérologie, Toulouse, France

$10{ }^{2}$ NOAA Chemical Sciences Laboratory and CIRES/University of Colorado, Boulder, CO, USA ${ }^{3}$ Max-Planck Institute for Meteorology, Hamburg, Germany

${ }^{4}$ Observatoire Midi-Pyrénées, Toulouse, France

${ }^{5}$ Atmospheric Chemistry Observations and Modeling, National Center for Atmospheric Research, Boulder, CO, USA

$15{ }^{6}$ Department of Civil and Environmental Engineering, The Hong Kong Polytechnic University, Hong Kong, China

${ }^{7}$ Royal Belgian Royal Institute for Space Aeronomy, Brussels, Belgium

Correspondence to: Thierno Doumbia (thierno.doumbia@aero.obs-mip.fr) 
Abstract. In order to fight the spread of the global COVID-19 pandemic, most of the world countries have taken control measures such as lockdowns during a few weeks to a few months. These lockdowns had significant impacts on economic and personal activities in many countries. Several studies using satellite and surface observations have reported important changes in the spatial and temporal distributions of atmospheric pollutants and greenhouse gases. Global and regional chemistry-transport model studies are being performed in order to analyze the impact of these lockdowns on the distribution of atmospheric compounds. These modeling studies aim at evaluating the impact of the regional lockdowns at the global scale. In order to provide input for the global and regional model simulations, a dataset providing adjustment factors (AFs) that can easily be applied to global and regional emission inventories has been developed. This dataset provides, for the January-August 2020 period, gridded AFs at a $0.1 \times 0.1$ latitude/longitude degree resolution, on a

40 daily or monthly basis for the transportation (road, air and ship traffic), power generation, industry and residential sectors. The quantification of AFs is based on activity data collected from different databases and previously published studies. A range of AFs is provided at each grid point for model sensitivity studies. The emission AFs developed in this study are applied to the CAMS global inventory (CAMS-GLOB-ANT_v4.2_R1.1), and the changes in emissions of the main pollutants

45 are discussed for different regions of the world and the first six months of 2020. Maximum decreases in the emissions are found in February in Eastern China, with an average reduction of 20-30 \% in $\mathrm{NOx}, \mathrm{NMVOCs}$ and $\mathrm{SO}_{2}$ relative to the reference emissions. In the other regions, the maximum changes occur in April, with average reductions of 20-30 \% for NOx, NMVOCs and CO in Europe and North America and larger decreases (30-50\%) in South America. In India and African regions,

50 NOx and NMVOCs emissions are reduced by 15-30\%. For the others species, the maximum reductions are generally less than $15 \%$, except in South America, where large decreases in $\mathrm{CO}$ and $\mathrm{BC}$ are estimated. As discussed in the paper, reductions vary highly across regions and sectors, due to the differences in the duration of the lockdowns before partial or complete recovery.

The dataset providing a range of AFs (average and average \pm standard deviation) is called

55 CONFORM (COvid adjustmeNt Factor fOR eMissions) (https://doi.org/10.25326/88). It is distributed by the Emissions of atmospheric Compounds and Compilation of Ancillary Data (ECCAD) database (https://eccad.aeris-data.fr/).

\section{Introduction}

60 The COVID-19 pandemic has triggered different measures in most world countries to protect citizens from the spread of the Severe Acute Respiratory Syndrome-Coronavirus 2 (SARS-CoV-2). The first measures, which included strict lockdowns, started in China at the end of January 2020. As the pandemic was spreading all over the world, lockdowns or other measures were gradually implemented in Asia, Europe, Oceania, North and South America and Africa. The restriction during

65 the different lockdowns have resulted in significant changes in the emissions of greenhouse gases (Le Quéré et al., 2020; Liu et al., 2020) and reactive air pollutants (Forster et al., 2020; Venter et al., 2020). The impact of the reductions on the emissions of primary pollutants was assessed in different 
regions based on surface observations (e.g. Shi and Brasseur, 2020; Lee et al., 2020; Kim et al., 2020) and satellite retrievals (e.g. Bauwens et al., 2020; Zhang et al., 2020; Diamond et al., 2020;

Biswal et al., 2020). Modeling studies have been initiated to investigate the changes in the global and regional distributions of tropospheric chemical compounds during the pandemics (Gaubert et al., 2020; Venter et al., 2020; Xing et al., 2020; Keller et al., 2020; Barré et al., 2020). These modeling studies are based on estimates of emissions for primary species, and on consistent changes of the emissions during the COVID-19 lockdown periods.

Here we present a global gridded dataset of emission adjustment factors (AFs) at a $0.1^{\circ} \mathrm{x} 0.1^{\circ}$ resolution and on a daily or monthly basis based on available activity data. Recent studies (Le Quéré et al., 2020; Forster et al., 2020) have discussed the changes in emissions at the global scale for several chemical compounds. In this paper, we propose a dataset of AFs for the individual sectors related to transportation including road, air and ship traffic, industry, residential activities and power generation. The advantage of such a dataset is that it can be applied directly to any global or regional inventory used in chemistry-climate models in a flexible way.

Section 2 describes the general methodology used in the development of the AFs. The following sub-sections analyze the sectoral activity data used to determine these factors. The availability of activity data depends strongly on the regions under consideration, and this might often lead to large regional uncertainties. We are therefore providing for each location and sector an estimated average, low and high (average \pm standard deviation) values of the AFs. In Section 3, we present and discuss the sectoral changes in emission AFs over selected regions as a function of time.

This paper discusses the dataset developed for the January-August 2020 period: the dataset is called CONFORM (COvid adjustmeNt Factor fOR eMissions) and will be regularly updated, to provide AFs until the end of 2020. The impact of the AFs on the emissions developed as part of the CAMS global anthropogenic emissions (Granier et al., 2019; Elguindi et al., 2020) are discussed for the 95 NMVOC, $\mathrm{CO}, \mathrm{NOx}, \mathrm{BC}, \mathrm{OC}$ and $\mathrm{SO}_{2}$ species in Section 3.5.

\section{Methodology}

To quantify the amount of the corresponding global gridded daily/monthly changes, the adjustment factors (AFs) are determined following the general methodology schematized in Figure 1. The four

100 different steps taken in our study to estimate the AFs are the following: 1) A data survey is first carried out to collect activity data for the power generation, industrial processes, residential, road transportation, shipping and aviation sectors. These sectors correspond to those considered in many global inventories such as the CAMS global anthropogenic emission inventory (CAMS-GLOBANT_v4.2_R1.1, Granier et al., 2019). The activity data used to estimate the emission AFs are 105 available from numerous sources for different time scales, depending on the geographical area. It should be noted that, in several regions of the world, accurate and/or up-to-date data are not publicly 
available, which could lead to a significant source of uncertainty in estimating reduction rates. Table 1 indicates the availability of data for the different sectors. Some of these data are used to support our analysis and contribute to the estimation of uncertainties on the AFs; 2) The collected data are

110 then analyzed and an intercomparison of the changes in activity data from datasets providing similar or equivalent parameters are performed. The dataset that provides the most detailed and reliable data is then chosen. The non-gridded AFs are calculated for each country, state or province according to the availability of activity data, as detailed in the following sections; 3) The gridded daily/monthly files per sector are obtained by assigning the value of the AFs at the country/state/province level to 115 each corresponding grid cell; and 4) Finally, a comparison of the AFs derived from this study with other published data is performed, together with an evaluation of their impact on emissions, using the CAMS-GLOB-ANT_v4.2_R1.1 inventory as a basis.

The dataset discussed in this paper covers the period from 1 January to 31 August 2020. It will be regularly updated to account for the latest available activity data information.

The AFs are calculated as the ratio between the activity data for a given sector and day or month, and the median value of the activity data over the five week-period starting on 1 January 2020 . The median value is calculated from 1 January to 4 February for almost all regions, except for China where the first lockdown started on 23 January 2020 in the Hubei province. The reference values for China's activity data is taken as the median value of the first three weeks (i.e. from 1 to 21 January 2020). We have chosen January 2020 as a reference period (pre-COVID-19), because detailed activity data such as mobility data are only publicly available for the year 2020 .

\subsection{Road transportation}

Several studies related to the COVID-19 pandemic have used the Google COVID-19 Community Mobility data (https://www.google.com/covid19/mobility/) (Forster et al., 2020; Guevara et al., 135 2020). This dataset provides the number of visitors to specific locations based on mobile phone locations (e.g. parks, grocery and pharmacy stores, workplaces, retail and recreation, train stations and residential) every day relative to a baseline value. This baseline is calculated as the median value over the five-week period from January $3^{\text {rd }}$ to February $6^{\text {th }} 2020$. We use measurements up to 31 August 2020 for all countries for which data are available (about 133 countries). For the USA, the

140 analysis was performed for each state. Google daily data are provided at country/state level and generally cover several local areas (i.e. subregion or city). For example, in the USA, Google spans the 50 states and the District of Columbia, as well as several cities in each state. The AFs for the road transportation sector are derived from the estimation of transit usage (i.e. public transportation including train stations, bus and subways) made by Google. In order to make the calculated AFs

145 comparable with those derived using the other data sources considered in this study, the AFs for the Google's categories are scaled as a function of the Google mobility data, so that their values are less than 1 for a reduction in activity and above 1 otherwise. 
It should be noted that Google mobility data are not available for all countries (e.g. China and for

nearly two thirds of African countries). Other datasets are providing mobility trends, such as the Apple mobility trend reports (https://covid19.apple.com/mobility) and the TomTom (https://www.tomtom.com/en gb/traffic-index/ranking/) traffic congestion index. Apple measures the number of requests for directions scaled relative to 13 January 2020, while TomTom provides the percentage of the differences in time spent on a trip compared to uncongested conditions. Google provides a better spatial coverage than the other two datasets. In Africa for example, Apple and TomTom data are available for 3 and 2 countries, respectively, while Google provides data for 26 African countries. In China, TomTom reports measurements only for some cities. Unlike Google and Apple, TomTom markets its data, which are therefore not in open access. In order to evaluate the Google dataset, a regional comparison with Apple mobility data was performed (Supplementary

160 Information, Figures S1-2). First, we looked separately at one Apple category (driving measurements, generated by counting the number of requested directions in transit or public transport on Apple applications) and three Google categories (retail/pharmacy, workplaces and grocery shopping destinations) according to three regions (Europe, USA and the rest of the world $(\mathrm{ROW})$ ). The comparisons of temporal series show that, in general, Apple driving displays much

165 larger variations than the Google mobility changes (Figure S1). However, the patterns of the average values of the four categories show a significant decrease in Europe of up to $57 \%$ for Apple driving and of 57, 65 and $31 \%$ for Google workplaces, retail and grocery, respectively. The corresponding values in the USA are 43, 16, 41 and $40 \%$, respectively, while those in the ROW are 61, 31, 60 and $48 \%$. A comparison between monthly Google's non-residential (i.e. combining grocery, 170 workplaces, transit and retail) and Apple driving data, which can be considered as equivalent categories, displays high correlation coefficients varying from 0.79 to 0.97 depending on the region (Figure S2). The data of these two categories agree relatively well, particularly during the first months of the COVID-19 pandemic (February to May) when lockdowns were strict in most regions. The largest discrepancies are observed from June to August, especially in Europe and the USA.

175 These differences are likely due to the fact that the two datasets do not represent the same parameters: Apple bases their values on the volume of directions requests on phone applications while Google uses mobile phone locations.

Comparisons of the changes in the ground transportation sector for the different mobility datasets 180 have been performed in recent studies (Forster et al., 2020; Le Quéré et al., 2020). The correlation coefficients between Google and Apple transit categories calculated in our study are in line with the value of 0.8 reported by Forster et al. (2020), for the February to June period. Liu et al. (2020) show trends from both Google and TomTom mobility datasets with the same order of magnitude during the first quarter of 2020. This analysis highlights the importance in the choice of the data to be considered in the estimation of changes based on activity data, especially for the more recent months, as well as for the future, when the dataset will be extended. Based on this analysis, we have used the Google Mobility data for estimating the AFs in regions where data are available. 
In China, the AFs for road transportation were calculated based on Baidu Migration Scale index (https://qianxi.baidu.com/, available for China only). These indices are aggregated from migration flows within China, based on the positioning requests on Baidu Map Services. The index indicates the ratio between the number of people traveling in a city and the population of this city. The data are available only from 1 January to 2 May 2020 and cover about 343 Chinese cities in all provinces. Baidu officially stopped updating the dataset on its platform on 8 May 2020. At that date, the values of the mobility indices are relatively close to those of January 2020 before the spread of the COVID19 virus. Therefore, in the absence of other mobility data publicly available in China, and in order to cover the whole period (January to August), we assume that there was no change in road traffic in China after May 2020. This hypothesis has been verified by comparing changes in the Baidu Migration Scale Index with the relative difference of TomTom congestion levels for some Chinese

200 provinces (Beijing, Tianjin, Chongqing and Shanghai). TomTom archived data are not freely available, but we were able to retrieve directly from published graphs the weekly changes in 2020 relative to the same periods in 2019. The results show a strong similarity between the values given by these two datasets for the period covered by the Baidu dataset, with a correlation coefficient of 0.9 (Figure S3). This comparison allows us to conclude that our method of calculating the AFs (i.e.

205 ratio between the activity data for a given sector and day or month and the median value of this activity over the five week-period) is consistent with changes in 2020 relative to the same period in 2019.

\section{$210 \quad 2.2$ Industrial processes}

This sector includes industrial production processes such as steel and cement production, manufactured products from fossil fuel combustion, and represents a significant part of the emission sources of atmospheric pollutants. The 2020 data concerning industrial production are, however, not

215 publicly available for many countries/regions. We used the crude steel production from the world steel association (Table 1), which is provided on a monthly basis, to estimate the rate of change in the industrial sector. Due to the difficulties to access the daily data in this source category, we assumed that changes in Google's workplace measures, which represent the percentage of people travelling to/from their workplaces, are representative of changes in industrial activities during the

220 lockdowns. To verify our hypothesis, we compared the calculated monthly average AFs based on Google's workplace data for selected countries with those derived from crude steel productions (Figure S4). The average change in the first eight months of 2020 relative to the same periods in 2019 in crude steel production for the 24 countries shown in Figure S4 is $17 \%$, while the corresponding value using Google's workplace measures is $27 \%$. This indicates a fair agreement

225 between the two datasets. However, there are large differences in some countries between these data. For example, in Europe the maximum change in crude steel production is $24 \%$ compared to $59 \%$ in Google's workplace category, suggesting a large uncertainty in the AFs for the industry sector. 


\subsection{Power generation}

The power sector emission AFs were estimated by compiling several sources such as the total electricity load from the ENTSO-E (European Network of Transmission System Operators for Electricity) transparent platform for the European Union and the United Kingdom, the regional

235 electricity demand from the EIA (Energy Information Administration) for the United States, the daily reports of the electricity generation from fossil fuel including coal, lignite and gas, Naptha and Diesel provided by the POSOCO (Power System Operation Corporation) for India, the thermal electricity production from the ONS (Operator of the National Electricity System) for Brazil and the daily power generation provided by the United Power system of Russia. We also used the local

240 electricity demand data in Singapore. For Canada, we assumed that the data in Ontario are representative of power generation trends (Table 1). It should be noted that we did not apply any temperature correction to the electricity load. Liu et al. (2020) indicated that the COVID-19 and related restrictions explain about $85 \%$ of the reduction in the power sector from January to March and only $15 \%$ are attributed to the temperature effect. For the rest of the world where data on 245 electricity demand or thermal production are not publicly available, we estimate the AFs based on the data published by Le Quéré et al. (2020).

\subsection{Air transportation and shipping}

250

Due to a lack of public daily data on air transportation to determine the AFs related to the large decline in passenger flights, we used the monthly data published by the Knowledge Center on Migration and Demography (KCMD) Dynamic Data Hub (Table 1). In addition to the observed passenger volumes from around the world, the KCMD provides air traffic scenarios covering the

255 COVID-19 period. Five scenarios are provided (Iacus et al., 2020). We selected the scenario called EUROC-L (L-shaped version) based on the Eurocontrol air traffic data, which provides global upto-date monthly average air volumes. To assess the representativeness of the KCMD estimates, we compared the EUROC-L scenario data with the number of international scheduled flights from 14 countries in 2020 provided by the OAG (Official Aviation Guide)

260 (https://www.oag.com/coronavirus-airline-schedules-data). The results indicated that, when considering the global average, trends from both datasets are relatively similar, with a significant decrease of up to $65 \%$ for OAG and $80 \%$ for KCDM in April, May and June compared to the reference value in January 2020. However, since July there has been a slow recovery towards the pre-lockdown values (Figure S5, Supplementary Information). EUROC-L seems to overestimate the 265 changes during the period when restrictions were the most severe, especially in China, Japan and South Korea. In contrast, there is an underestimation of trends since July 2020 in most of the countries as shown in Figure S5. A lockdown for the whole of China was declared on February 10, 2020 and the country had its air traffic heavily impacted on the following days. This disruption does not appear in the KCDM data. This analysis leads us to the conclusion that the KCDM data can only 
be used to complement the OAG data. It should be noted that KCDM data have the advantage of being available for more than 230 countries and are regularly updated.

Detailed data on 2020 international and national shipping are not publicly available yet. In this study, the changes in shipping activity are determined based on the weekly containership port calls during

275 the 31 weeks of 2020 (covering the period from 1 January to 2 August) compared to the same period in 2019 and reported by the United Nations Conference on Trade and Development (UNCTAD) (https://unctad.org/news/covid-19-shipping-data-hints-some-recovery-global-trade). UNCTAD provides official statistics from marine traffic for different regions: North America (Canada, Mexico, United States), East Coast of South America (Argentina, Brazil, Uruguay), Northern Europe 280 (Belgium, Germany, Netherlands), Southern Europe (France, Italy, Spain), Northern and Western Africa (Egypt, Morocco, Nigeria, Togo), Eastern and Southern Africa (Kenya, Tanzania, South Africa), South Asia (Bangladesh, India, Pakistan, Sri Lanka), South East Asia (Indonesia, Malaysia, Singapore, Thailand), China and Hong Kong. Weekly values are directly extracted from graphs and monthly AFs are derived.

\subsection{Residential sector}

In this study, the AF calculations for the residential sector are performed using measurements from Google's residential category, which covers most of the countries in the world. Google's residential 290 category represents the duration during which people are constrained to their home through lockdown. This duration represents the additional time that people spent in places of residence due to the restrictions. In the CAMS-GLOB-ANT inventory, the residential sector includes mainly emissions due to cooking, heating and auxiliary engines that primarily use biomass or fossil fuels in households. The emissions from this sector vary according to the geographical zone due to the

295 difference in lifestyles. We consider that, when people stay at home, the impact on heating use is moderate: heating systems generally continue to operate during working hours, at a lower intensity. The extra time spent at home contributes significantly to other domestic activities, namely cooking, heating water and activities using fossil fuels. Based on this analysis, we expect an increase in residential combustion during the lockdown period.

300 In China, due to the lack of data, we use residential emissions published by Le Quéré et al. (2020) which are based on electricity consumption for the city of London for the first fourth months of 2020. For the rest of the study period, we assumed that there is no change in the AFs for the residential sector in China.

\section{Results}

\subsection{Adjustment factors for the transportation sector}

This section focuses on the changes in the transportation sector which include road transportation,

air traffic and shipping. 


\subsubsection{Road transportation}

The AFs related to road transportation provide significantly lower emission values, when compared to typical values before the restrictions, and present large regional variations. Figure 2 displays the averages AFs in Europe, USA, South America, China, Africa and the rest of the world since the beginning of 2020. The uncertainty for each region and country is determined by the standard deviation from individual values of all the countries in the region or from local measurements in the country. We also calculated the minimum and maximum values within specific regions from all the values calculated for each of the countries in this region. An average daily reduction of up to $60 \%$ in mid-April is shown in most regions of the world. In China and Europe, the reductions reached a maximum in mid-February and late March, respectively. In China, the lockdowns started on 23 January and the period from 24 January to 2 February coincides with Chinese Spring Festival holidays during which business activities were reduced. It has been reported that short term emission reductions associated with the Spring Festival in China were about $10 \%$ in January 2009 (Lin et al.,

325 2011; Zhang et al., 2020). The 2020 reductions in emissions from road transport are significantly larger and peak during February 2020, with no rebound after the Chinese New Year holiday (e.g. Kraemer et al., 2020; Miyazaki et al., 2020). In the USA where the variability is largest, the average decrease reached $40 \%$ in mid-April. In Africa, the largest decrease occurred at the same period as in Europe and the USA, but with values of about $50 \%$, while the average decrease was much larger in South America, reaching $70 \%$. These results are in agreement with the changes during the first quarter of 2020 reported by Le Quéré et al. (2020) and based on Apple, TomTom mobility trends and local traffic data for the USA provided by MS2 (Modern Transportation Analytics) Corporation. Based on the standard deviations calculated from the data for each region, an uncertainty of \pm 10 to $\pm 30 \%$ is associated with the estimated AFs, depending on the region. Figure 2 also indicates that some regions recovered to the pre-COVID-19 situation more rapidly than others (e.g. the USA, the European countries and China), while most countries in South America, Africa and the rest of the world continue to be affected by lockdown measures at the end of the period discussed in this paper.

\section{$340 \quad$ 3.1.2 Air traffic and shipping}

As discussed in Section 2, the changes in air traffic were calculated using the monthly global scheduled flights from OAG combined with the passenger volumes reported from KCMD. Figure 3a displays the monthly air traffic AFs with an average value as low as to 0.2 (a decline of $80 \%$ ) in most of countries in the world. This large decrease spreads over several months from April to June, while the aviation activity started to rebound in July but the activity remained below the prepandemic level.

As a consequence of the global lockdown measures, activities in shipping also declined. Due to the lack of up-to-date data, we assume that changes in container ship port calls, published on the UNCTAD website, are representative of trends in shipping activities. The average global change as 
well as the associated standard deviation and upper and lower limits values are represented in Figure 3 b. The number of port calls by container ship globally decline from January to August to $7 \pm 6 \%$ relative to 2019. However, changes vary across regions. For example, we found a monthly reduction in North America and Europe up to $18 \%$ and $20 \%$ in June, respectively. These reductions are in the lower limit values of 20-30\% reported from the literature and based on forecast and published reports (Le Quéré et al., 2020; Liu et al., 2020).

\subsection{Adjustment factors for the industrial sector}

360 Our estimates of AFs for the industry sector are derived from the Google's workplace measures. Results show that the level of activity in the industrial sector over the 214 considered countries started, on average, falling down in mid-March when most countries began to take restrictive measures. The average AF reaches a maximum decrease (up to $40 \%$ ) in April relative to the reference period (i.e., pre-COVID-19) before increasing until May. It remained relatively stable

365 (approximately $20 \%$ reduction) from the beginning of June to August. These levels of change are in line with those reported in Forster et al. (2020) for the first half of 2020. As Figure 4 illustrates, the average AF displays rather similar patterns across the different regions considered, except in China. Based on Google data, industrial operations were subject to an important decrease in almost all regions, with a maximum daily average $\mathrm{AF}$ value close to 0.4 (60 \% reduction) in the European and South American countries and in many other countries, especially in late March and early April. However, contrarily to the others countries, European countries show a second maximum daily average reduction ( $\mathrm{AF}=0.75$ or $25 \%$ ) in mid-August, with a magnitude lower than the first peak. The impact of the lockdowns on the industrial activities is somewhat smaller in the USA, Africa and in the rest of the world, with a maximum reduction of about 30-40\% relative to the pre-COVID-19

pandemic values. In China, AF fell at the end of February to its minimum average value of 0.60 (40 $\%$ decrease), but increased to 0.73 (27\% decrease) in March and remained lower than the level before the pandemic. The uncertainty range (using 2 standard deviations) associated with the emission AFs for the industrial sector is evaluated to \pm 20 to $\pm 30 \%$, depending on the region. It is noteworthy that for almost all countries, the pre-pandemic level of industrial activity has not been reached, eight months after the beginning of the first lockdown announcements.

\subsection{Adjustment factors for the residential sector}

Contrarily to other sectors, the AFs for the residential sector estimated from Google's mobility data

show an increase of 20 to $30 \%$ at its maximum, during the peaks of the lockdowns, depending on the region (Figure 5). The average percentage increase is $30 \%$ in South America, while the maximum average AF value in China is less than 1.10 (i.e. about $10 \%$ increase). As for the others activity sectors, there is a variability of $10 \%$ in all regions, as shown by the standard deviation. This increase in the adjustment factors is mostly due to the fact that, in most countries, schools were closed and teleworking was widespread. As a result, most people in countries affected by strict 
lockdowns had to stay home most of the time. The impact of lockdowns on residential emissions is quite uncertain, as all the data including fuel use in commercial and residential buildings necessary to quantify this impact are not yet available worldwide. Our study, based on Google's residential measures reflecting time spent by people at their home, leads to increased emissions from the residential sector. However, the study of Liu et al. (2020), based on population-weighted heating degree days combined with EDGAR 2018 residential emission, suggests a global decrease. The estimated uncertainty range in the emission AFs for residential sector reached $\pm 20 \%$. Our global estimate is consistent with an increase of around $5 \%$ in activity data from the residential sector, mainly during the strict lockdown period, estimated in Le Quéré et al. (2020).

\subsection{Adjustment factors for the power generation sector}

The COVID-19 pandemic has implications on the share of energy use in industry, commercial and domestic operations. In order to quantify the impact of the lockdowns in this sector, we used the data of electricity demand. The global demand experienced a maximum average decrease of $20 \%$ (AF=

405 0.8) between late March and early April when the restrictions were most stringent in Europe, USA, Africa and many other countries (Figure 4). From mid-June, there is an increase in the demand for electricity consumption in the USA which reaches a maximum value of about $20 \%$ at the end of July and beginning of August but seems to be followed by a slow decrease. This can possibly be explained by an important demand in the commercial and residential sectors. It should be noted that

410 most African countries did not implement strict lockdowns: as discussed in Section 2, activity data are available mostly for North African countries and for South Africa, which experienced severe restrictions. The maximum decline ranged from 20 to $30 \%$ in South American countries and in China. As for the other sectors, the peak of the reduction factor for energy in China and South American countries happened at the end of February and early April, respectively. Our results are in

415 line with the average reduction of $20 \%$ or more of electricity demand in mid-March in several countries, as reported in the 2020 IEA energy review report (IEA, 2020). We estimated an uncertainty of $\pm 15 \%$ for the power sector, in agreement with the average values of the standard deviations calculated over all regions.

We also notice that the variability in the AFs for this sector is smaller than for to the other sectors.

420 This can be partly explained by the low uncertainty in the energy sector data.

\subsection{Impact on surface emissions}

The estimations of emission AFs for six emission sectors (road transportation, industry, power generation, residential, shipping and aviation) discussed in the previous sections are provided by the 425 CONFORM dataset on a daily basis, except for aviation and shipping calculated on a monthly basis, for the period from January to August 2020 at a $0.1^{\circ} \mathrm{x} 0.1^{\circ}$ grid resolution. This dataset has been also used in the Gaubert et al. (2020) paper which provides and analysis of the changes in secondary atmospheric pollutants during the 2020 COVID-19 Pandemic. 
430 The impact of the AFs changes on the total emissions (sum of emissions from transportation (road and non-road traffic), industry, residential, power and shipping) has been analyzed for different compounds and selected regions, using the anthropogenic CAMS-GLOB-ANT_v4.2_R.1.1 emission inventory (Granier et al., 2019; Elguindi et al., 2020). This dataset provides daily emissions of the main atmospheric compounds, including speciated volatile organic compounds at a $0.1^{\circ} \mathrm{x} 0.1^{\circ}$ 435 resolution, from 2000 to 2020 . Version R.1 of the CAMS-GLOB-ANT_v4.2 dataset incorporates the MEIC1.3 regional inventory for China described by Zheng et al. (2018).

The percentage change in 2020 emissions compared to the reference 2020 emissions is shown in Figure 7 for the main pollutants (NOx, CO, SO $2, \mathrm{BC}, \mathrm{OC}$ and NMVOCs) in Eastern China $\left(20^{\circ} \mathrm{N}-\right.$ $\left.45^{\circ} \mathrm{N}, 80^{\circ} \mathrm{E}-125^{\circ} \mathrm{E}\right)$, Europe $\left(35^{\circ} \mathrm{N}-70^{\circ} \mathrm{N}, 20^{\circ} \mathrm{W}-20^{\circ} \mathrm{E}\right)$, North America $\left(20^{\circ} \mathrm{N}-50^{\circ} \mathrm{N}, 135^{\circ} \mathrm{W}-35^{\circ} \mathrm{W}\right)$,

440 South America $\left(60^{\circ} \mathrm{S}-20^{\circ} \mathrm{N}, 90^{\circ} \mathrm{S}-35^{\circ} \mathrm{S}\right)$, India $\left(05^{\circ} \mathrm{N}-30^{\circ} \mathrm{N}, 60^{\circ} \mathrm{E}-90^{\circ} \mathrm{E}\right)$ and Africa $\left(40^{\circ} \mathrm{S}-30^{\circ} \mathrm{N}\right.$, $\left.20^{\circ} \mathrm{W}-40^{\circ} \mathrm{E}\right)$. The error bars indicate the estimated lower and upper limits of the changes in emissions. The changes are strongly dependent on the chemical species and regions. This reflects the differences in the contribution of each sector to the total emissions for the different countries.

445 In agreement with the changes in the activity data previously shown, the reductions are highest in February in Eastern China region for all species, except OC for which a relatively small increase is observed during that month. The average monthly NOx emissions in Eastern China derived from this study decreased in February 2020 by $29 \%$ (24-37\%) compared to the reference emission scenario (i.e. without COVID-19 effect). The NMVOCs emissions decrease significantly, by $22 \%$ $450 \quad(15-29 \%)$, and rather similar decreases are estimated for $\mathrm{SO}_{2} . \mathrm{BC}$ and $\mathrm{CO}$ show maximum average reductions of 8 and $10 \%$, respectively in the Eastern China region, while OC shows a slight increase of $1.6 \%$ for February.

In the rest of the world, NOx emissions exhibit large decreases (13-42\%) during the strictest shutdown period (i.e. in April) when almost all sectors of activity slowed down or stopped, since the main sectors contributing to NOx emissions are road transportation and industries.

In Europe, the average reduction in NOx is $25 \%(20-35 \%)$ in April. These values are in the same order of magnitude as the mean change of $-33 \%$ reported in Guevara et al. (2020) for Europe for 460 the period from 23 March to 26 April 2020. For $\mathrm{SO}_{2}$, the average reduction in Europe calculated by Guevara et al. (2020) is in the same order of magnitude as our low estimation range of 9-23\% (average value of $14 \%$ ) in April. However, the percentage decline in NMVOCs emissions (21-40\% with an average of $34 \%$ as for April) is much higher than the value from Guevara et al. (2020). Solvents and industrial processes are the main sectors contributing to anthropogenic NMVOCs 465 emissions: in our study, the changes in the solvents sectors, for which no data are yet available, are assumed similar to the changes related to the industrial sector. The way the decrease in solvent emissions are handled in the different studies could explain the large differences in the changes in NMVOCs emissions in different regions. European $\mathrm{CO}, \mathrm{SO}_{2}$ and $\mathrm{BC}$ emissions during the lockdowns decreased by an average of 8,14 and 18\% in April, respectively, relative to the reference 
The results show that the lockdowns led to an average reduction in NOx emissions in the USA of 21 $\%$ (15-35\%) during April, while these values reach $43 \%$ (30-53\%) in South American regions, 29 $\%(22-42 \%)$ in India and $13 \%(8-19 \%)$ in Africa. For NMVOCs, the maximum average reduction is $33 \%(21-43 \%)$ in the USA in April, while these values reach $55 \%(27-57 \%)$ in South America, $14 \%(2-19 \%)$ in India and $19 \%(1.4-21 \%)$ in Africa.

The changes in OC emissions are different from the changes seen for other species, because of the large share of the residential sector in the OC emissions. These results give us a global overview of the impact of restriction measures in different parts of the world.

Figure 8 displays the spatial distribution in four geographical regions of the absolute difference between the COVID-19 and the standard 2020 anthropogenic emissions for NOx, a pollutant strongly affected by changes in human activity. The figure indicates that the emissions declined in all geographical areas during the months under study, with the main differences happening in urban areas where the share of road transport is largest. It can be noticed that the total emission change in China results mostly from the significant decrease of emissions in the densely populated and heavily industrialized North China Plain and megacities (Figure 8a). These changes in NOx emissions are mostly driven by changes in road transport activity. The largest decreases in large cities of Europe, USA and India are highlighted on the figure.

\section{Conclusions}

The restrictions and lockdowns resulting from the COVID-19 pandemic since the end of January 2020 have had important social, economic and environmental consequences. In this study, we have 495 provided an estimate of adjustment factors (AFs) to quantify the changes in global emissions of major atmospheric pollutants during the lockdown periods. This dataset can be easily applied to the emissions used in chemistry-climate global and regional models to simulate the impacts of the reduced human activity on the atmospheric composition and climate. To this purpose, we analyzed activity data from various sectors representative of transportation (road, air and ship), industry, residential and power generation. The resulting dataset provides daily or monthly sectoral AFs on a $0.1^{\circ} \times 0.1^{\circ}$ resolution over the globe, and can be used to quantify regional patterns in the distributions of emissions during the COVID-19 pandemic. When applied to the CAMS-GLOB-ANT_v4.2_R1.1 emissions dataset, large changes are estimated, with maximum decreases in the emissions in February in Eastern China, with an average reduction of $20-30 \%$ in NOx, NMVOCs and $\mathrm{SO}_{2}$

505 emissions. In other regions, the maximum changes occur in April, with average reductions of 20$30 \%$ for NOx, NMVOCs and CO in Europe and North America and larger decreases (30-50\%) in South America. In India and Africa, NOx and NMVOCs emissions decline by up to 15-30 \%. For the others species, the maximum reductions are generally less than $15 \%$, except in the South American countries where large decreases in $\mathrm{CO}$ and $\mathrm{BC}$ are estimated. The patterns of these reductions show large differences at the regional level. 
We acknowledge that the lack of data for some activity sectors in several regions and the absence of accurate information on all sectors might cause significant uncertainties in the estimation of the AFs. For that reason, besides average values, the dataset also includes low and high estimation of the AFs

515 for the period over January-August 2020. This should give an estimate of the uncertainties on the distribution of chemical species in models. The AFs obtained in this study will be extended at least until the end of the year 2020, and will be revised and updated as new or improved information on economic and mobility activity becomes available.

\section{Data availability}

The average estimated daily/monthly gridded AFs for the sectors considered in this study, i.e. transportation including air traffic and shipping, industries, residential and power generation are available as NetCDF files for the global domain at a resolution of $0.1^{\circ} \mathrm{x} 0.1^{\circ}$ resolution. The uncertainties are also provided as the average \pm standard deviation. The acronym of the dataset is CONFORM (COvid adjustmeNt Factor fOR eMissions), and it is available at https://doi.org/10.25326/88. The files can be openly accessed through the Emissions of atmospheric Compounds and Compilation of Ancillary Data (ECCAD) database with a login account (https://eccad.aeris-data.fr/). In the ECCAD database, the dataset can be directly accessed using the link: https://eccad.aeris-data.fr/essd-conform/.

\section{Author contributions.}

535 Conceptualization: Thierno Doumbia, Claire Granier

Production of emissions: Thierno Doumbia, Sabine Darras, Nellie Elguindi, Claire Granier

Collection of datasets: Thierno Doumbia, Yiming Liu, Xiaoqin Shi, Tao Wang

Analysis of the AFs results: Thierno Doumbia, Idir Bouarar, Simone Tilmes, Benjamin Gaubert, Trissevgeni Stavrakou

540 Test of the AFs in atmospheric models: Benjamin Gaubert, Adrien Deroubaix, Forrest Lacey

Writing -original draft: Thierno Doumbia, Claire Granier, Guy Brasseur

Writing -review and editing: All authors.

Competing interests. The authors declare that they have no conflict of interest.

Acknowledgments. We acknowledge the support of the AQ-WATCH European project, a HORIZON 2020 Research and Innovation Action (GA 870301), the ESA ICOVAC project, and the SEEDS EU project. The CAMS-GLOB-ANT dataset has been developed with the support of the CAMS (Copernicus Atmosphere Monitoring Service, https://atmosphere.copernicus.eu/), operated by the European Centre for Medium-Range Weather Forecasts on behalf of the European 
Commission as part of the Copernicus Programme. The ECCAD database (eccad.aeris-data.fr) is supported by the French AERIS data infrastructure (aeris-data.fr). This material is based upon work supported by the National Center for Atmospheric Research, which is a major facility sponsored by the US National Science Foundation under cooperative agreement no. 1852977. T.W. and Y.L. 555 acknowledge support by the Hong Kong Research Grants Council (T24-504/17-N and APolyU502/16). 


\section{References}

Barré, J., Petetin, H., Colette, A., Guevara, M., Peuch, V.-H., Rouil, L., Engelen, R., Inness, A., Flemming, J., Pérez García-Pando, C., Bowdalo, D., Meleux, F., Geels, C., Christensen, J. H., Gauss, M., Benedictow, A., Tsyro, S., Friese, E., Struzewska, J., Kaminski, J. W., Douros, J., Timmermans, R., Robertson, L., Adani, M., Jorba, O., Joly, M., and Kouznetsov, R.: Estimating lockdown induced European $\mathrm{NO}_{2}$ changes, Atmos. Chem. Phys. Discuss., https://doi.org/10.5194/acp-2020-995, in review, 2020.

600 Bauwens, M. S. Compernolle, T. Stavrakou, J.-F. Müller, J. van Gent, H. Eskes, P. F. Levelt, R. van der A, J. P. Veefkind, J. Vlietinck, H. Yu, C. Zehner: Impact of coronavirus outbreak on $\mathrm{NO}_{2}$ pollution assessed using TROPOMI and OMI observations, Geophys. Res. Lett., 47, doi:10.1029/2020GL087978, 2020.

605 Biswal, A., V. Singh, S. Singh, A. P. Kesarkar, K. Ravindra, R. S. Sokhl, M. P. Chipperfield, S. S. Dhomse, R. J. Pope, T. Singh and S. Mor: COVID-19 lockdown induced changes in $\mathrm{NO}_{2}$ levels across India observed by multi-satellite and surface observations, Atmos. Chem. Phys., https://doi.org/10.5194/acp-2020-1023, 2020.

610 Diamond, M. S. and R. Wood: Limited Regional Aerosol and Cloud Microphysical Changes Despite Unprecedented Decline in Nitrogen Oxide Pollution During the February 2020 COVID-19 Shutdown in China, Geophys. Res. Lett., 47, https://doi.org/10.1029/2020GL088913, 2020.

Elguindi, N., Granier, C., Stavrakou, T., Darras, S., Bauwens, M., Cao, H., C. Chen, H.A.C. Denier van 615 der Gon, O. Dubovik, T.M. Fu, D.K. Henze, Z. Jiang, S. Keita, J.J.P. Kuenen, J. Kurokawa, C. Liousse, J.F. Muller, Z. Qu, F. Solmon, B. Zheng: Intercomparison of magnitudes and trends in anthropogenic surface emissions from bottom-up inventories, top-down estimates, and emission scenarios, Earth's Future, 8, e2020EF001520. doi:10.1029/2020EF001520, 2020.

620 Forster, P. M., H. I. Forster, M. J. Evans, M. J. Gidden, C. D. Jones, C. A. Keller, R. D. Lamboll, C. Le Quéré, J. Rogelj, D. Rosen, C.-F. Schleussner, T. B. Richardson, C. J. Smith and S. T. Turnock: Current and future global climate impacts resulting from COVID-19, Nat. Clim. Chan., 10, 913-919, doi:10.1038/s41558-020-0883-0, 2020.

625 Gaubert, B., I. Bouarar, T. Doumbia, Y. Liu, T. Stavrakou, A. Deroubaix, S. Darras, N. Elguindi, C. Granier, F. Lacey, J.F. Müller, X. Shi, S. Tilmes, T. Wang, and G. P. Brasseur: Global Changes in Secondary Atmospheric Pollutants during the 2020 Covid-19 Pandemic, in review for J. Geophys. Res., https://doi.org/10.1002/essoar.10504703.1 2020.

630 Granier, C., S. Darras, H. Denier van der Gon, J. Doubalova, N. Elguindi, B. Galle, M. Gauss, M. Guevara, J.-P. Jalkanen, J. Kuenen, C. Liousse, B. Quack, D. Simpson, K. Sindelarova: The Copernicus Atmosphere 
Monitoring Service global and regional emissions, Copernicus Atmosphere Monitoring Service (CAMS) report, doi:10.24380/d0bn-kx16, 2019.

635 Guevara, M., O. Jorba, A. Soret, H. Petetin, D. Bowdalo, K. Serradell, C. Tena, H. Denier van der Gon, J. Kuenen, V.-H. Peuch, C. P. Garcia-Pando: Time-resolved emission reductions for atmospheric chemistry modelling in Europe during the COVID-19 lockdowns, Atmos. Chem. Phys., https://doi.org/10.5194/acp2020-686, 2020.

640 IEA (International Energy Agency), Global Energy Review 2020, IEA, Paris https://www.iea.org/reports/global-energy-review-2020, 2020.

Iacus, S.M., F. Natale, C. Santamaria, S. Spyratos, M. Vespe: Estimating and projecting air passenger traffic during the COVID-19 coronavirus outbreak and its socio-economic impact, Saf. Sci., 129, 645 Article 104791, 10.1016/j.ssci.2020.104791, 2020.

Keller, C. A., Evans, M. J., Knowland, K. E., Hasenkopf, C. A., Modekurty, S., Lucchesi, R. A., Oda, T., Franca, B. B., Mandarino, F. C., Díaz Suárez, M. V., Ryan, R. G., Fakes, L. H., and Pawson, S.: Global Impact of COVID-19 Restrictions on the Surface Concentrations of Nitrogen Dioxide and 650 Ozone, Atmos. Chem. Phys. Discuss. https://doi.org/10.5194/acp-2020-685, in review, 2020.

Kim, H. C., Kim, S., Cohen, M., Bae, C., Lee, D., Saylor, R., Bae, M., Kim, E., Kim, B.-U., Yoon, J.H., and Stein, A.: Quantitative assessment of changes in surface particulate matter concentrations over China during the COVID-19 pandemic and their implications for Chinese economic activity, Atmos.

655 Chem. Phys. Discuss., https://doi.org/10.5194/acp-2020-821, in review, 2020.

Kraemer, M.U.G., Yang, C.-H., Gutierrez, B., Wu, C.-H., Klein, B., Pigott, D. M., open COVID-19 data working group, L. du Plessis, Faria, N. R., Li, R., Hanage, W. P., Brownstein, J. S., Layan, M., Vespignani, A., Tian, H., Dye, C., Cauchemez, S., Pybus, O., Scarpino, S. V.: The effect of human mobility and control measures on the COVID-19 epidemic in China, https://doi.org/10.1126/science.abb4218, 2020.

Lee, J. D., W. S. Drysdale, D. P. Finch, S. E. Wilde and P. I. Palmer: UK surface $\mathrm{NO}_{2}$ levels dropped by $42 \%$ during the COVID-19 lockdown: impact on surface $\mathrm{O}_{3}$, Atmos. Chem. Phys. Disc., doi:10.5194/acp-2020-838, 2020.

Le Quéré, C., R. B. Jackson, M. W. Jones, A. J. P. Smith, S. Abernethy, R. M. Andrew, A. J. De-Gol, D. R. Willis, Y. Shan, J. G. Canadell, P. Friedlingstein, F. Creutzig and G. P. Peters: Temporary reduction in daily global $\mathrm{CO}_{2}$ emissions during the COVID-19 forced confinement, Nat. Clim. Chang. 10, 647-665, doi:10.1038/s41558-020-0797-x, 2020.

Lin, J.T.; McElroy, M.B.: Detection from space of a reduction in anthropogenic emissions of nitrogen oxides during the Chinese economic downturn, Atmos. Chem. Phys., 11, 8171-8188, 2011. 
675 Liu, Z., Ciais, P., Deng, Z., Lei, R., Davis, S. J., Feng, S., Zheng, B., Cui, D., Dou, X., Zhu, B., Guo, R., Ke, P., Sun, T., Lu, C., He, P., Wang, Y., Yue, X., Wang, Y., Lei, Y., Zhou, H., Cai, Z., Wu, Y., Guo, R., Han, T., Xue, J., Boucher, O., Boucher, E., Chevallier, F., Tanaka, K., Wei, Y., Zhong, H., Kang, C., Zhang, N., Chen, B., Xi, F., Liu, M., Bréon, F-M., Lu, Y., Zhang, Q., Guan, D., Gong, P., Kammen, D. M., He, K., Schellnhuber, H. J.: Near-real-time monitoring of global $\mathrm{CO}_{2}$ emissions reveals the effects of the COVID
https://doi.org/10.1038/s41467-020-18922-7, 2020

Myllyvirta, L.: Coronavirus temporarily reduced China's $\mathrm{CO}_{2}$ emissions by a quarter, Carbon Brief https://www.carbonbrief.org/analysis-coronavirus-has-temporarily-reduced-chinas-co2-emissions-bya-quarter, 2020.

Miyazaki, K., Bowman, K., Sekiya, T., Jiang, Z., Chen, X., Eskes, H., M. Ru, Y. Zhang, and D. Shindell: Air quality response in China linked to the 2019 novel coronavirus (COVID-19) lockdown, Geophys. Res. Lett., 47, e2020GL089252. https:// doi.org/10.1029/2020GL089252, 2020.

Shi, X. and G. P. Brasseur: The response in air quality to the reduction of Chinese Economic Activities during the COVID-19 Outbreak, Geophys. Res. Lett., 47, 11, doi:10.1029/2020GL088070, 2020.

Venter, Z.S., K. Aunan, S. Chowdhury, and J. Lelieveld: COVID-19 lockdowns cause global air pollution declines, Proc. Nat. Acad. of Sci., 117 (32) 18984-18990, doi:10.1073/pnas.2006853117, 2020.

Xing, J., Li, S., Jiang, Y., Wang, S., Ding, D., Dong, Z., Zhu, Y., and Hao, J.: Quantifying the emission changes and associated air quality impacts during the COVID-19 pandemic in North China Plain: a response modeling study, Atmos. Chem. Phys. Discuss., https://doi.org/10.5194/acp-2020-522, in review, 2020

Zhang, R., Y. Zhang, H. Lin, X. Feng, T.M. Fu, and Y. Wang: NOx Emission Reduction and Recovery during COVID-19 in East China, Atmosphere, 11, 433, DOI:10.1038/s41558-020-0797-x, 2020.

Zheng, B., Tong, D., Li, M., Liu, F., Hong, C., Geng, G., Li, H., Li, X., Peng, L., Qi, J., Yan, L., Zhang, Y., Zhao, H., Zheng, Y., He, K., and Zhang, Q.: Trends in China's anthropogenic emissions since 2010 as the consequence of clean air actions, Atmos. Chem. Phys., 18, 14095-14111, https://doi.org/10.5194/acp-18-14095-2018, 2018. 


\section{Tables}

Table 1: Data sources of activity data used to estimate the emission AFs. In this table, Rest Of World (ROW) refers to all world countries except China.

\begin{tabular}{|c|c|c|c|}
\hline Sectors & $\begin{array}{l}\text { Country/ } \\
\text { Region }\end{array}$ & Data & Data sources \\
\hline \multirow{2}{*}{$\begin{array}{l}\text { Road } \\
\text { transport } \\
\text { (TRO) }\end{array}$} & China & 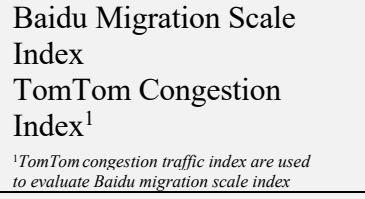 & $\begin{array}{l}\text { China Data Lab, 2020, "Baidu Mobility Data", } \\
\text { https://doi.org/10.7910/DVN/FAEZIO } \\
\underline{\text { https://www.tomtom.com/en_gb/traffic-index/ranking }}\end{array}$ \\
\hline & $\begin{array}{l}\text { Rest Of } \\
\text { World } \\
\text { (ROW) }\end{array}$ & $\begin{array}{l}\text { Google's transit } \\
\text { stations category } \\
\text { Apple mobility }{ }^{2} \\
\text { 2Apple mobility data are used to evaluate } \\
\text { Google activity data }\end{array}$ & $\begin{array}{l}\text { https://www.google.com/covid19/mobility/ } \\
\underline{\text { https://covid19.apple.com/mobility }}\end{array}$ \\
\hline \multirow{2}{*}{$\begin{array}{l}\text { Residential } \\
\text { (RES) }\end{array}$} & China & $\begin{array}{l}\text { Emissions from } \\
\text { residential sector }\end{array}$ & Le Quéré et al. (2020) \\
\hline & ROW & $\begin{array}{l}\text { Google's residential } \\
\text { category }\end{array}$ & https://www.google.com/covid19/mobility/ \\
\hline \multirow{3}{*}{$\begin{array}{l}\text { Industrial } \\
\text { processes } \\
\text { (IND) }\end{array}$} & China & $\begin{array}{l}\text { Coal consumption from the } \\
\text { six main coal producers }\end{array}$ & $\begin{array}{l}\text { Myllyvirta } 2020 \\
\text { https://www.carbonbrief.org/analysis-coronavirus-has- } \\
\underline{\text { temporarily-reduced-chinas-co2-emissions-by-a-quarter }}\end{array}$ \\
\hline & ROW & $\begin{array}{l}\text { Google's workplaces } \\
\text { category }\end{array}$ & https://www.google.com/covid19/mobility/ \\
\hline & $\begin{array}{l}\text { World } \\
\text { (ROW + } \\
\text { China) }\end{array}$ & $\begin{array}{l}\text { Crude steel production } \\
{ }^{3} \\
{ }^{3} \text { Monthly used to help in the analysis of the } \\
\text { adjustment factors in the industrial sector, } \\
\text { estimated from Google's workplaces category. }\end{array}$ & https://www.worldsteel.org/ \\
\hline \multirow{8}{*}{$\begin{array}{l}\text { Power } \\
\text { Generation } \\
(\text { ENE) }\end{array}$} & India & $\begin{array}{l}\text { Production of Coal, } \\
\text { Lignite, and Gas Naphtha } \\
\text { and Diesel }\end{array}$ & $\begin{array}{l}\text { Power System Operation Corporation Limited } \\
\text { (https://posoco.in/reports/daily-reports/) }\end{array}$ \\
\hline & $\begin{array}{l}\text { USA (regional } \\
\text { data) }\end{array}$ & $\begin{array}{l}\text { Regional electricity } \\
\text { load }\end{array}$ & $\begin{array}{l}\text { Energy Information Administration (EIA) } \\
\text { (https://www.eia.gov/beta/states/states/ca/data/dashboar } \\
\text { d/electricity) }\end{array}$ \\
\hline & $\begin{array}{l}\text { Europe (country } \\
\text { level) }\end{array}$ & Total electricity load & $\begin{array}{l}\text { ENTSO-E Transparent platform } \\
\text { (https://transparency.entsoe.eu/dashboard/) }\end{array}$ \\
\hline & Brazil & Thermal Production & $\begin{array}{l}\text { Operator of the National Electricity System } \\
\text { (http://www.ons.org.br/Paginas/) }\end{array}$ \\
\hline & Russia & Power Generation & $\begin{array}{l}\text { United Power System of Russia } \\
\text { (http://www.so-ups.ru/index.php) }\end{array}$ \\
\hline & Singapore & Electricity demand & https://www.ema.gov.sg/Statistics.aspx \\
\hline & Canada & $\begin{array}{l}\text { Electricity demand } \\
\text { Ontario }\end{array}$ & http://reports.ieso.ca/public/Demand/ \\
\hline & $\begin{array}{l}\text { Other regions } \\
\text { (e.g. Asia, } \\
\text { Africa) }\end{array}$ & $\begin{array}{l}\text { Emissions from Power } \\
\text { sector }\end{array}$ & Forster et al. (2020) \\
\hline $\begin{array}{l}\text { Air } \\
\text { transportati } \\
\text { on }(A V I)\end{array}$ & $\begin{array}{l}\text { China and } \\
\text { ROW }\end{array}$ & $\begin{array}{l}\text { Projection of air traffic } \\
\text { volume }\end{array}$ & $\begin{array}{l}\text { Knowledge Center on Migration and Demography } \\
\text { (KCMD) Dynamic Data Hub } \\
\text { https://bluehub.jrc.ec.europa.eu/migration/app/index.html\# }\end{array}$ \\
\hline Shipping (SHP) & World & Container shipping & $\begin{array}{l}\text { United Nation Conference on Trade and Development } \\
\text { (UNCTAD) } \\
\text { https://unctad.org/news/covid-19-shipping-data-hints- } \\
\text { some-recovery-global-trade }\end{array}$ \\
\hline
\end{tabular}


https://doi.org/10.5194/essd-2020-348

Preprint. Discussion started: 11 January 2021

(c) Author(s) 2021. CC BY 4.0 License.

(c) (i)

\section{Figures}

720

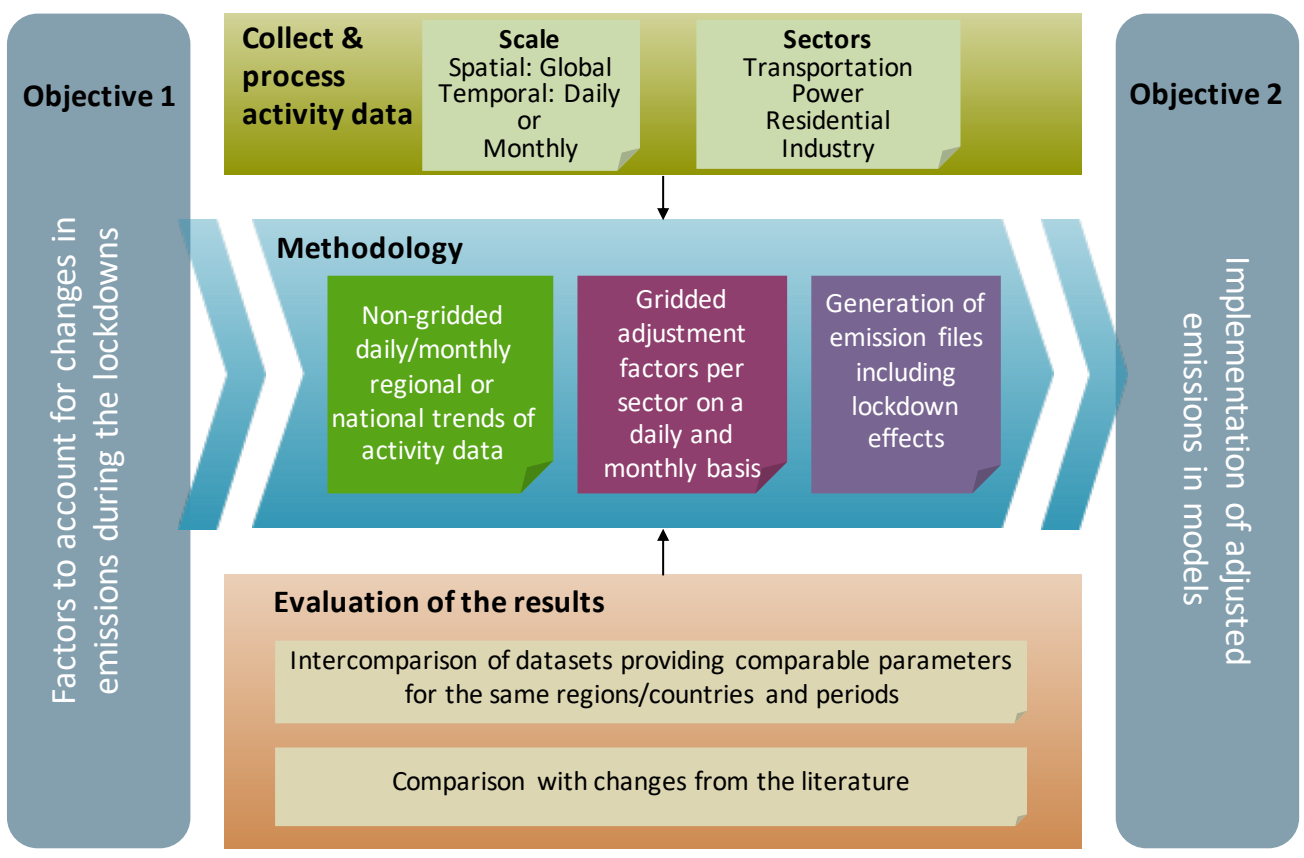

725 Figure 1: Schematic view of the different steps for estimating the emission adjustment factors (AFs). 

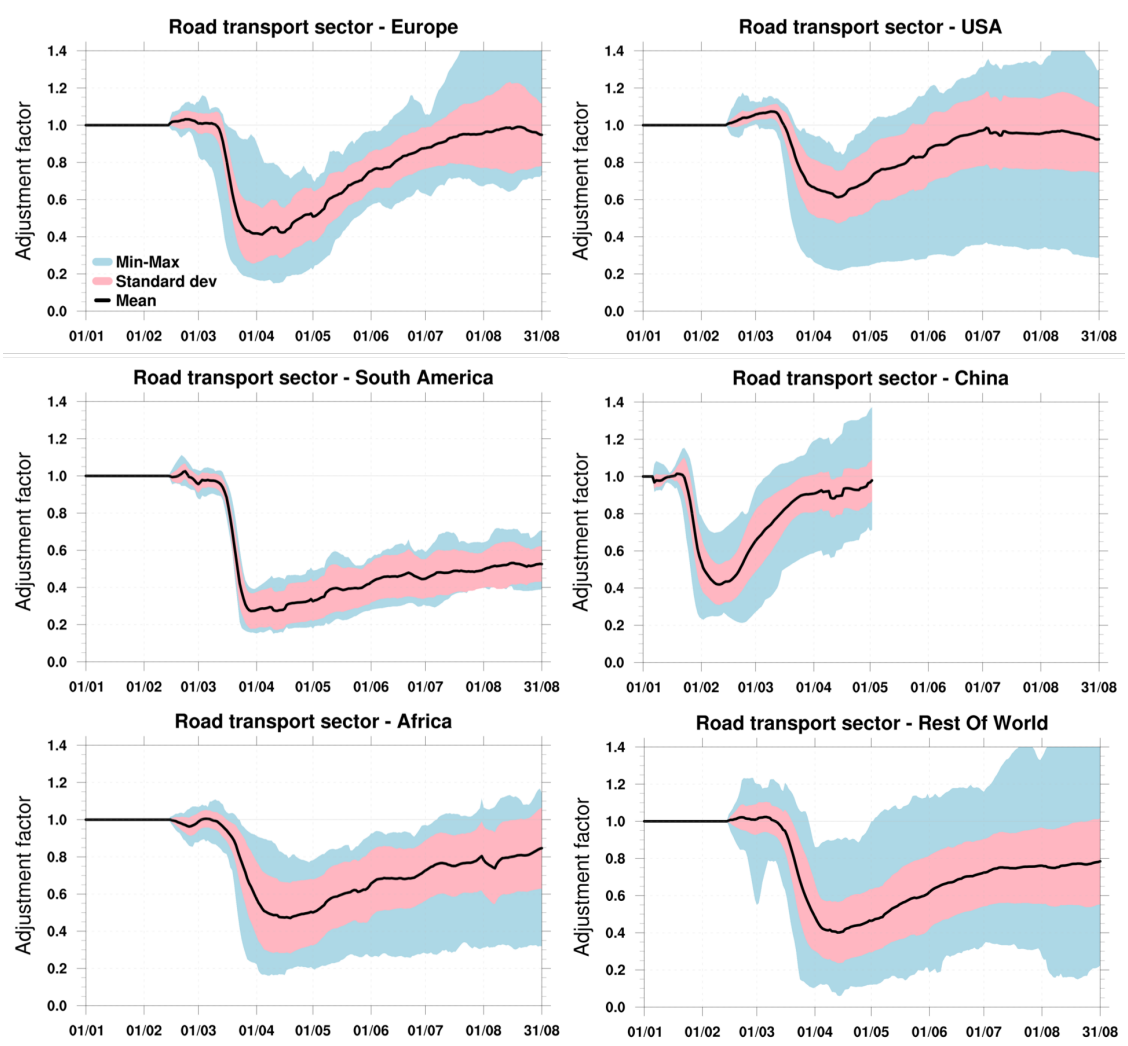

730 Figure 2: Daily AFs for the road transportation sector from January to August 2020 over Europe, USA, South America, China, Africa and the rest of the world. These estimations are derived from Google's transit category. The standard deviation values (light pink) result from the AFs for individual countries, states or provinces. The light blue color indicates the range of the minimum and maximum values.
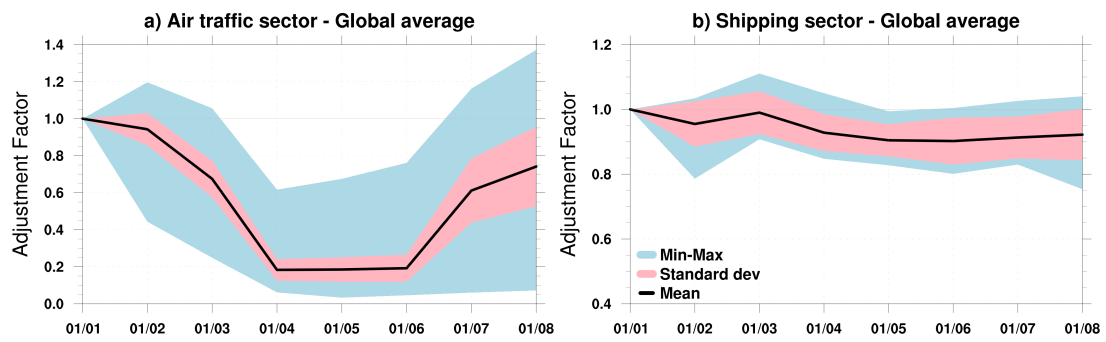

Figure 3: AF time series for a) air traffic and b) shipping as a function of month from January to August 2020. The standard deviation values (light pink) are calculated, based on the AFs of all 740 individual countries, while the light blue color indicates the range of the minimum and maximum values. 

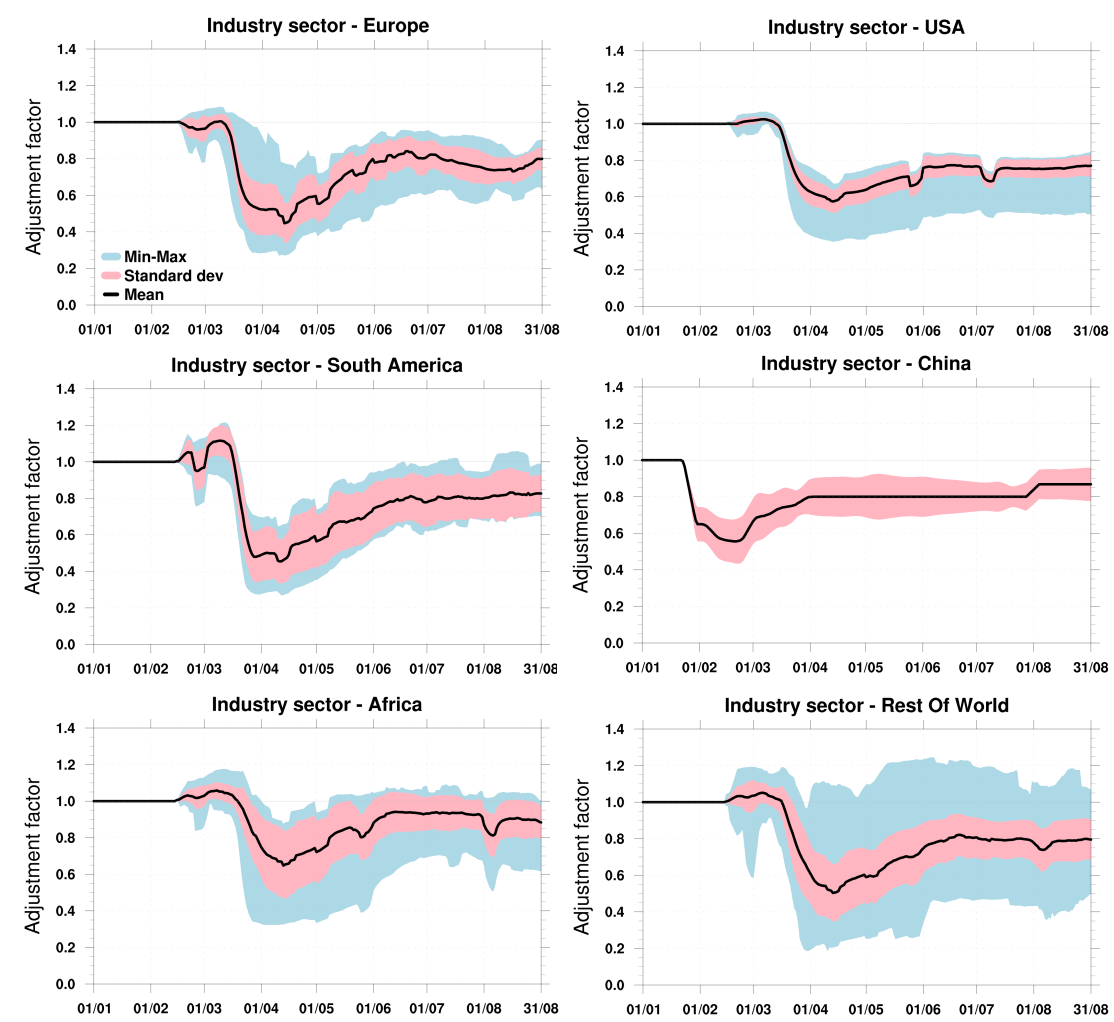

745 Figure 4: Daily AFs for the industrial sector from January to August 2020 over Europe, USA, South America, China, Africa and the rest of the world. These estimations are derived from Google's workplaces category. The standard deviation values (light pink) result from the AFs for individual countries, states or provinces. The light blue color indicates the range of the minimum and maximum values. 

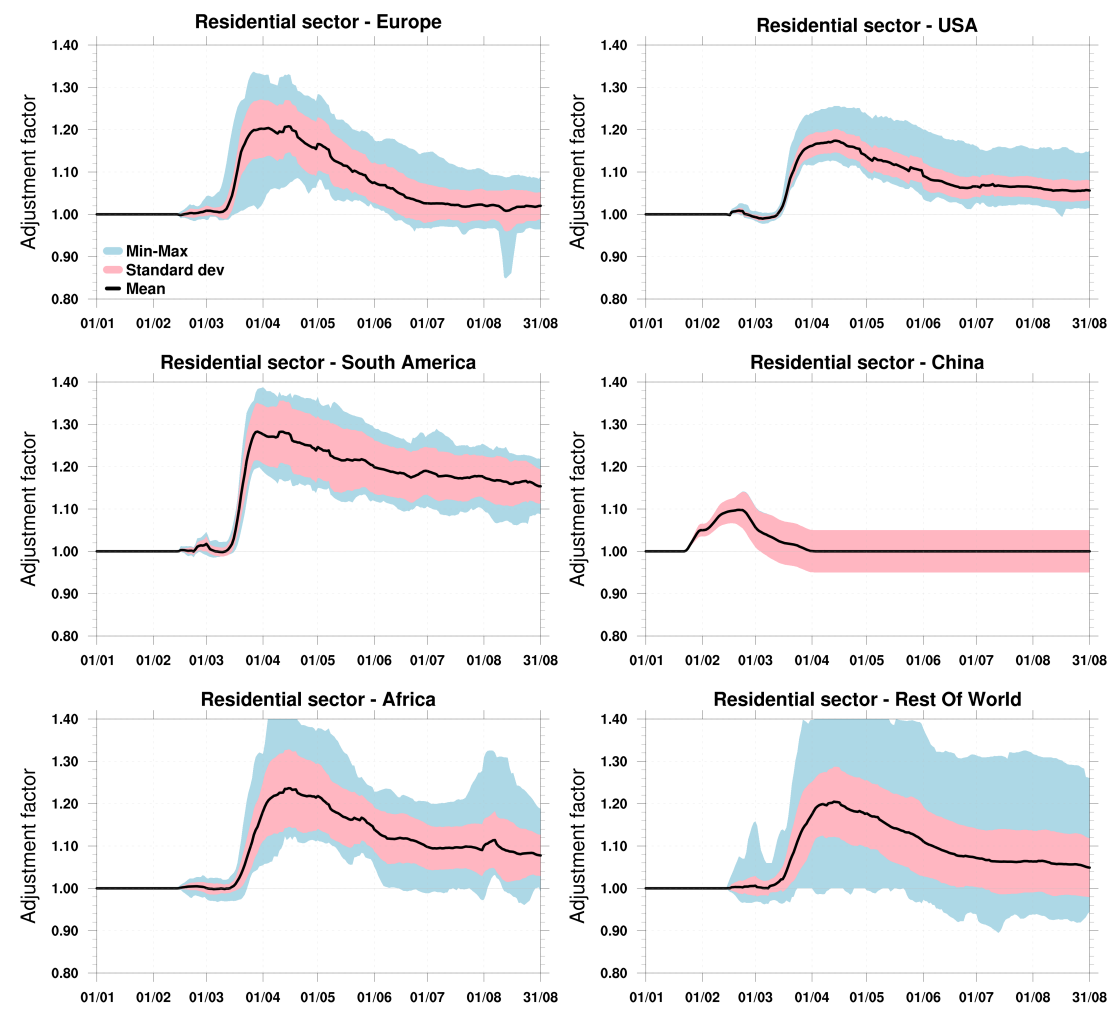

Figure 5: Daily AFs for residential sector from January to August 2020 over Europe, USA, South 755 America, China, Africa and the rest of the world. These estimations are derived from Google's residential category. The standard deviation values (light pink) result from the AFs for individual countries, states or provinces. The light blue color indicates the minimum and maximum values. 

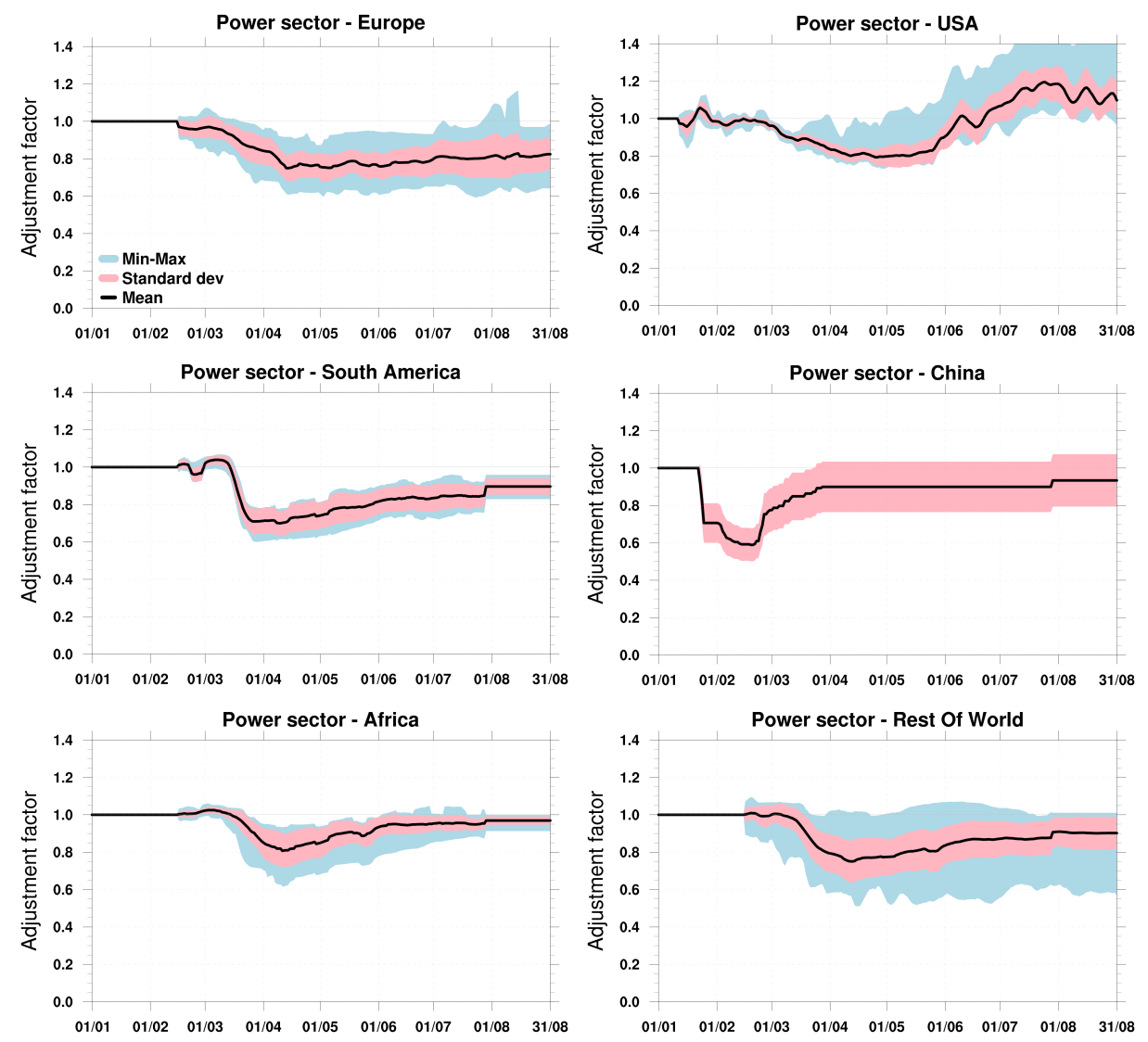

Figure 6: Daily AFs for power sector from January to August 2020 over Europe, USA, South America, China, Africa and the rest of the world. These estimations are derived from multiple data sources (Table 1). The standard deviation values (light pink) result from the AFs of the individual countries or states. The light blue color indicates the range of the minimum and maximum values. 

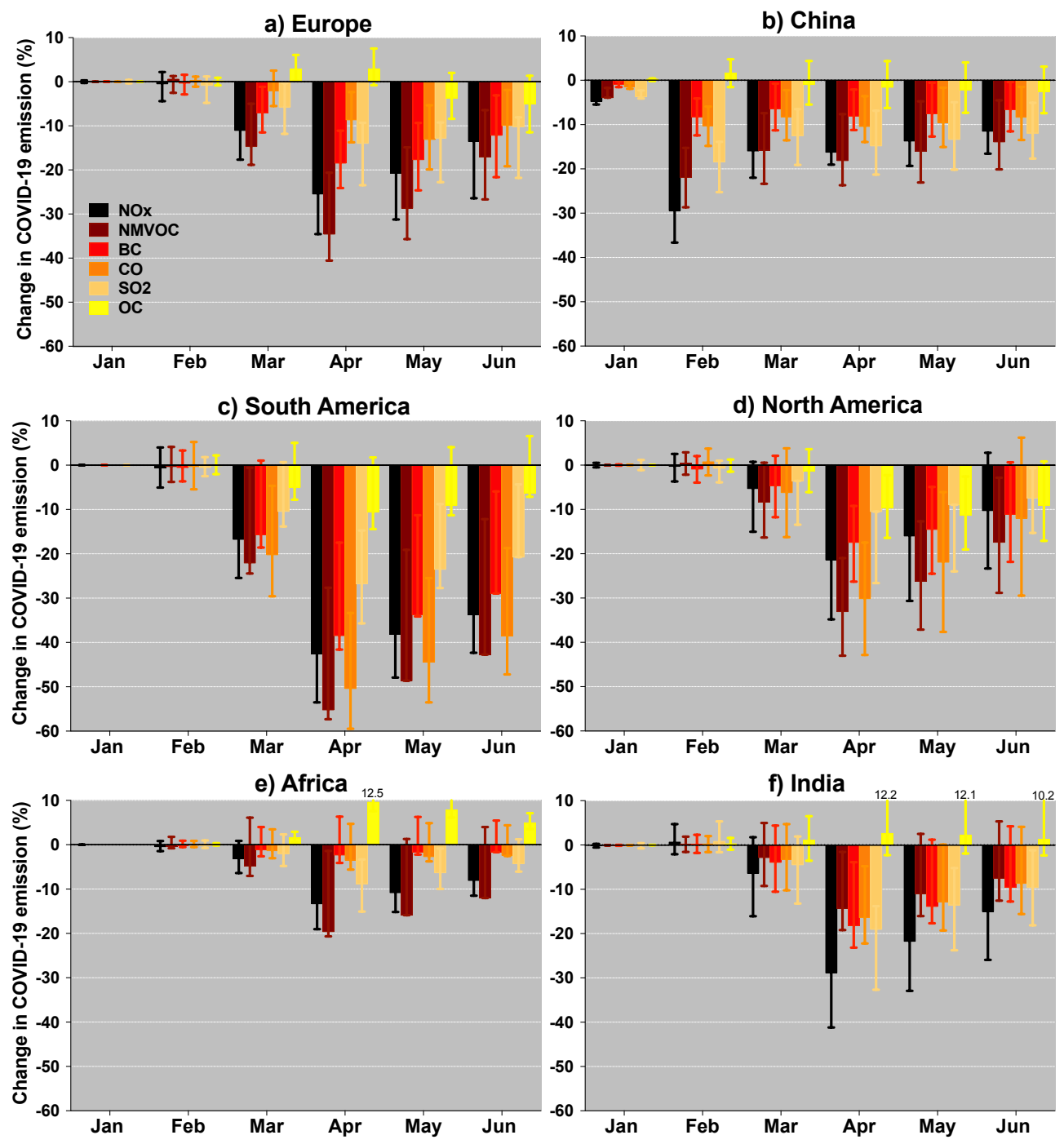

Figure 7: Relative change (COVID-19 - reference / reference) in total emissions (combination of

emissions from ground transportation, industry, power, residential and shipping), as a function of month for selected regions: a) Europe $\left(35^{\circ} \mathrm{N}-70^{\circ} \mathrm{N}, 20^{\circ} \mathrm{W}-20^{\circ} \mathrm{E}\right)$, b) Eastern China $\left(20^{\circ} \mathrm{N}-45^{\circ} \mathrm{N}\right.$, $\left.80^{\circ} \mathrm{E}-125^{\circ} \mathrm{E}\right)$, c) South America $\left(60^{\circ} \mathrm{S}-20^{\circ} \mathrm{N}, 90^{\circ} \mathrm{S}-35^{\circ} \mathrm{S}\right)$, d) North America $\left(20^{\circ} \mathrm{N}-50^{\circ} \mathrm{N}, 135^{\circ} \mathrm{W}-\right.$ $\left.35^{\circ} \mathrm{W}\right)$, e) Africa $\left(40^{\circ} \mathrm{S}-30^{\circ} \mathrm{N}, 20^{\circ} \mathrm{W}-40^{\circ} \mathrm{E}\right)$ and f) India $\left(05^{\circ} \mathrm{N}-30^{\circ} \mathrm{N}, 60^{\circ} \mathrm{E}-90^{\circ} \mathrm{E}\right)$. 


\section{a) China}

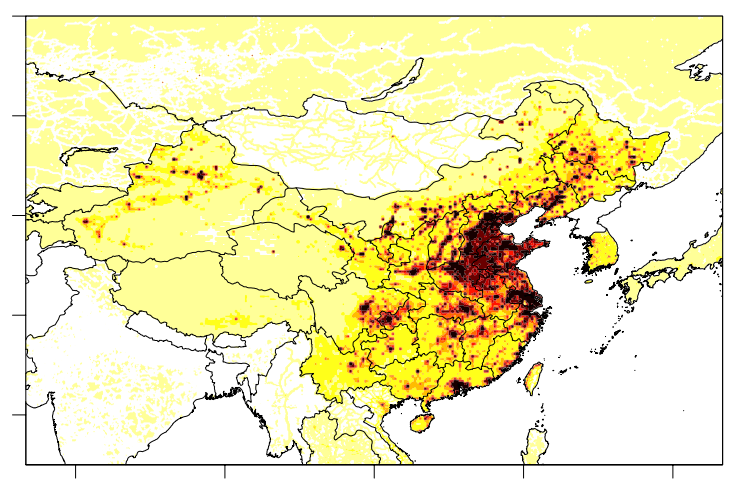

c) North America

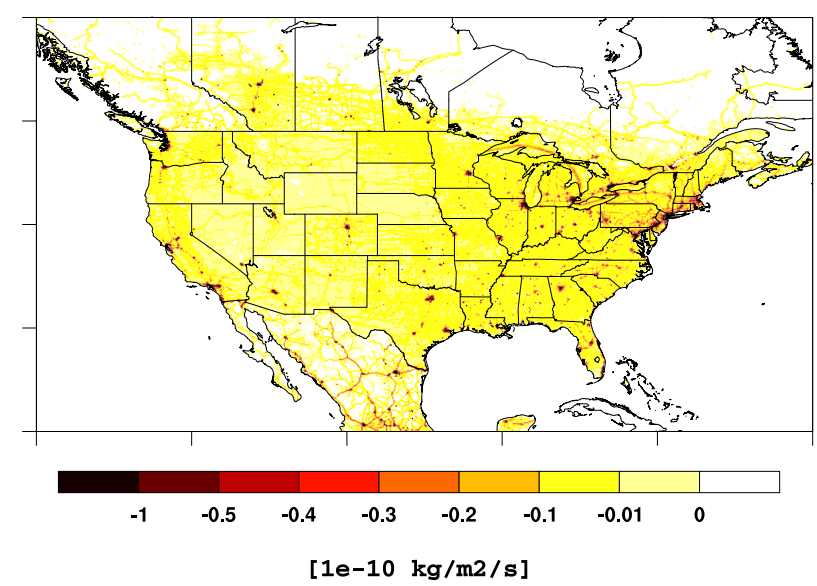

b) Europe

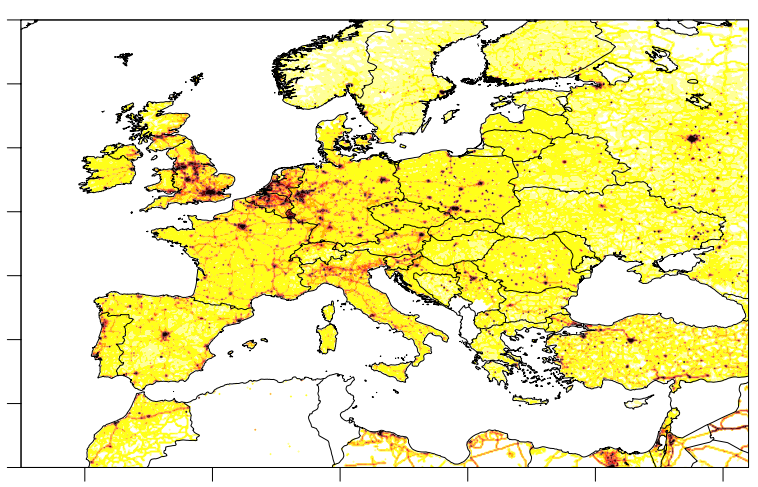

d) S. America April 2020

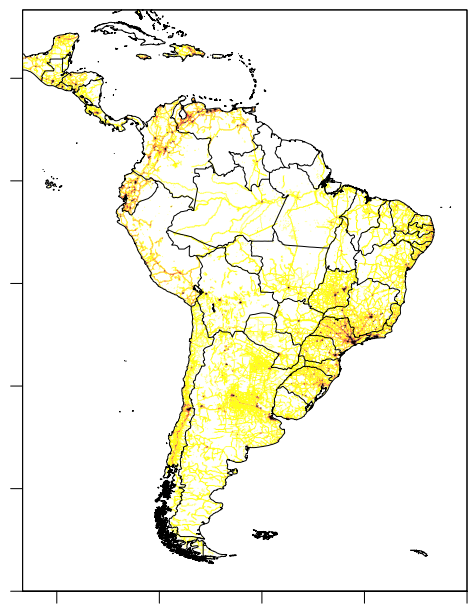

Figure 8: Spatial distribution of the absolute difference between COVID-19 and reference emissions of NOx with a focus on a) China, b) Europe, c) North America and d) South America regions. The figures correspond to the periods of highest reduction, i.e. in February for Eastern China China region and April for the other regions. 